\title{
Preparation of low-molecular-weight polyamide 6/ hydrotalcite intercalated nanocomposites via insitu polymerization
}

\author{
Z. Yan-wu*, J. Jun-qing \\ College of Chemical Engineering, Zhengzhou University, Zhengzhou, 450000, PR China
}

Received 19 November 2006; accepted in revised form 17 January 2007

\begin{abstract}
Low-molecular-weight PA6 (LMW-PA6)/hydrotalcite intercalated nanocomposites were prepared via insitu polymerization in the presence of organo-hydrotalcite with alanine as an initiator at $150{ }^{\circ} \mathrm{C}$. The results indicated that alanine in the interlayer gallery of hydrotalcite doesn't change the interlayer distance of hydrotalcite, while it can initiate the polymerization of $\varepsilon$-caprolactam. There exsists $\gamma$ crystalloid of LMW-PA6 in LMW-PA6/hydrotalcite intercalated nanocomposites. The molecular weight distribution of LMW-PA6 in the intercalated nanocomposites has two peaks and the added amounts of organo-hydrotalcite hardly influence molecular weight of LMW-PA6.
\end{abstract}

Keywords: nanomaterials, low-molecular-weight polyamide 6, hydrotalcite, in situ polymerization, alanine

\section{Introduction}

Polyamide 6 (PA6) has been widely used as engineering plastic and fibres and extensively researched since 1930s while low-molecularweight PA6 (LMW-PA6) is seldom studied though it can be used to improve rheology behavior of coatings and processing behavior of polyamide or as modifiers of fillers in polymer composites. In the past ten years, PA6 nanocomposites were prepared by melt-compounding and in situ polymerization [1-6]. But most research on PA6 nanocomposites focused on the use of silicate clays as nanoparticles due to its commercially availability, high aspect ratio and considerable cation-exchange capacity. Silicate clays can improve the mechanical and gas barrier properties of polymer materials. Compared with silicate clays, hydrotalcite is a synthetic layered inorganic mineral composed of positively charged layers and interlayer-exchangeable anions $[7,8]$. It has been widely used as catalyst, ion

*Corresponding author, e-mail: zhangyanwu@zzu.edu.cn

(C) BME-PT and GTE exchanger, absorbent, ceramic precursor, and in organic-inorganic nanocomposites [9-11].

Among numerous hydrotalcites $\mathrm{Mg}-\mathrm{Al}$ hydrotalcite is an excellent inorganic flame retardant and smoke suppressant. Although many reports about the intercalation of organic anions into hydrotalcite have been published, relatively few reports have discussed the incorporation of hydrotalcite into polymers. Andrea Sorrentino incorporated $\mathrm{Mg}-\mathrm{Al}$ hydrotalcite into a biodegradable poly( $\varepsilon$-caprolactone) by high energy ball milling [12]. Wen-Fu Lee prepared nanocomposite superabsorbents containing intercalated hydrotalcite via insitu polymerization [13]. Fabrice L studied the difference of in situ polymerization between hydrotalcite and hydrocalumite host structures [14]. However PA6 or LMW-PA6 nanocomposite containing hydrotalcite is seldom researched.

Usually PA6 is prepared by ring-opening polymerization at high temperature or anion polymerization. Though the rate of anionic polymerization is 
very rapid, polymerization conditions are rigorous and polymerization procedures are not easily controllable. During preparation of polyamide, other monomers are introduced into the chains of polyamide to endow them with functional properties such as biodegradability or change its crystallization structure [15-17].

Considering application of LMW-PA6, excellent rheology behavior is favored. In this paper DL-alanine was used to initiate ring-opening polymerization and copolymerization of $\varepsilon$-caprolactam. Therefore chain structure of LMW-PA6 was changed to improve its change rheology behavior. LMW-PA6/hydrotalcite nanocomposites were prepared via in situ polymerization in the presence of hydrotalcite at lower temperature. The effect of hydrotalcite on cystalloid of LMW-PA6, molecular weight of polymer and the structure of composites prepared was detailed studied.

\section{Experimental}

\subsection{Materials}

$\varepsilon$-caprolactam $\left[\mathrm{COC}_{5} \mathrm{H}_{10} \mathrm{NH}\right](\mathrm{CP})$, DL-alanine $\left[\mathrm{CH}_{3} \mathrm{CH}\left(\mathrm{NH}_{2}\right) \mathrm{COOH}\right]$ (BR) and Oleic acid $\left[\mathrm{C}_{17} \mathrm{H}_{33} \mathrm{COOH}\right](\mathrm{AR})$ were purchased and used as received. N, N-dimethyl formamide (DMF) was of reagent analytical grade and distilled before used. $\mathrm{Mg}-\mathrm{Al}$ hydrotalcite with high crystallinity was synthesized according to the 'Urea' method [18].

\subsection{Intercalation of alanine into hydrotalcite}

Because alanine anion exists only in basic solutions, ion-exchange must be carried out in a basic solution. $11.76 \mathrm{~g}$ DL-alanine, $20 \mathrm{~g}$ Mg-Al hydrotalcite and $5.28 \mathrm{~g} \mathrm{NaOH}$ was put into $1000 \mathrm{ml}$ de-ionized water. The solution was stirred for 5 hours at $70^{\circ} \mathrm{C}$ and then filtered. The solid product was washed three times with de-ionized water. At last the obtained powder was dried at $70^{\circ} \mathrm{C}$ in vacuum for 24 hours. The final product was called as organo-hydrotalcite.

\subsection{Insitu polymerization of $\varepsilon$-caprolactam initiated by alanine in the presence of hydrotalcite}

A $250 \mathrm{ml}$ four-neck flask, equipped with a reflux condenser, a stirring rod, and a thermometer, was charged with $\varepsilon$-caprolactam $\left[\mathrm{COC}_{5} \mathrm{H}_{10} \mathrm{NH}\right]$ (I), alanine $\left[\mathrm{CH}_{3} \mathrm{CH}\left(\mathrm{NH}_{2}\right) \mathrm{COOH}\right]$ (II), oleic acid $\left[\mathrm{C}_{17} \mathrm{H}_{33} \mathrm{COOH}\right](\mathrm{III})$, water and organo-hydrotalcite. To avoid the thermal oxidative degradation of $\varepsilon$-caprolactam and alanine nitrogen purge was used during the procedure. The polymerization temperature was set at $150^{\circ} \mathrm{C}$ and the polymerization was terminated after 6 hours. The viscous liquid products were washed three times with hot water and dried under vacuum. Amounts of the reagents in each run were listed in Table 1.

\subsection{Characterization}

The structure of hydrotalcite was characterized with wide angle X-ray diffraction (WAXRD) on a Japan D/max-RB 12-kW diffractometer using $\mathrm{CuK} \alpha$ as a radiation source, operated at $40 \mathrm{kV}$ and $100 \mathrm{~mA}$. The scanning rate and the scanning range were $6^{\circ} \mathrm{C} / \mathrm{min}$ and from $2^{\circ} \mathrm{C}$ to $70^{\circ} \mathrm{C}$ respectively. Content of intercalated analine was determined by thermogravimetric analysis (TGA) on Seiko TG/DT 6200 Thermogravimetric analyzer and with absorbance analysis on Shimadazu UV-2450 ultraviolet-visible spectrophotometer. For TGA characterization the samples dried at $100^{\circ}$ under vacuum for 12 hours were heated under nitrogen at a heating rate of $10^{\circ} \mathrm{C} / \mathrm{min}$ from $100^{\circ} \mathrm{C}$ to $700^{\circ} \mathrm{C}$. For absorbance analysis samples was washed with deionized water for three times and filtrate was collected to analyze analine content.

Molecular weight of polymer was measured using gel permeation chromatography (GPC) method with Agilent 1100 series (Agilent Technologies). The temperature of columns was set at $50^{\circ} \mathrm{C}$. Polystyrene was chosen as standard samples. Samples were dissolved in $\mathrm{DMF}$ at $50^{\circ} \mathrm{C}$ with sonication and those containing hydrotalcite were

Table 1 Amounts of the reagents in each run

\begin{tabular}{|c|c|c|c|c|c|c|}
\hline Runs & $\begin{array}{c}\text { E-caprolactam (I) } \\
{[\mathrm{g}]}\end{array}$ & $\begin{array}{c}\text { Alanine (II) } \\
{[\mathrm{g}]}\end{array}$ & $\begin{array}{c}\text { oleic acid (III) } \\
\text { [g] }\end{array}$ & $\begin{array}{c}\text { water } \\
{[\mathrm{ml}]}\end{array}$ & $\begin{array}{c}\text { organo-hydrotalcite } \\
{[\mathrm{g}]}\end{array}$ & $\begin{array}{c}-\mathrm{NH}_{2(\mathrm{I}+\mathrm{II})} /-\mathrm{COOH}_{\mathrm{III}} \\
{[\mathrm{mol} / \mathrm{mol}]}\end{array}$ \\
\hline $1 \#$ & 20 & 3.4 & 30.3 & 5 & 0 & 2.00 \\
\hline $2 \#$ & 20 & 3.4 & 30.3 & 5 & 2.7 & 2.14 \\
\hline $3 \#$ & 20 & 3.4 & 30.3 & 5 & 5.4 & 2.28 \\
\hline $4 \#$ & 20 & 0 & 30.3 & 5 & 5.4 & 1.92 \\
\hline
\end{tabular}


dipped in hydrochloric acid solution for 24 hours to remove hydrotalcite before dissolved.

\section{Results and discussion}

\subsection{WAXRD patterns of hydrotalcite and organo hydrotalcite}

Higher crystallization of $\mathrm{Mg}$ - $\mathrm{Al}$ hydrotalcite is helpful to elucidate accurately the effect of hydrotalcite on the polymerization and the structure of the products. Figure 1. shows WAXRD patterns of $\mathrm{Mg}$-Al hydrotalcite and organo-hydrotalcite. In WAXRD patterns of Mg-Al hydrotalcite the narrow peaks and smooth base lines show the characteristics of a highly crystalline layered structure of $\mathrm{Mg}-\mathrm{Al}$ hydrotalcite. After hydrotalcite was intercalated by alanine, the typical peak (003) $2 \theta$ of hydrotalcite changes little and still lies at about $11.6^{\circ}$. This is different from other intercalated hydrotalcites. The typical peak (003) $2 \theta$ usually shift to smaller angles and the interlayer distance of hydrotalcite increases for other anion intercalated hydrotalcites [9]. The reason may be that molecule size of alanine isn't large enough to increase the interlayer distance. Due to higher alanine adsorption quantity of hydrotalcite determined by TGA in the following section, there should be intercalated alanine in the gallery of hydrotalcite.

\subsection{Content of intercalated alanine}

In addition to modifying hydrotalcite alanine can initiate the polymerization of $\varepsilon$-caprolactam and may become incorporated into the polymer chains as a co-monomer. So the quantity of alanine

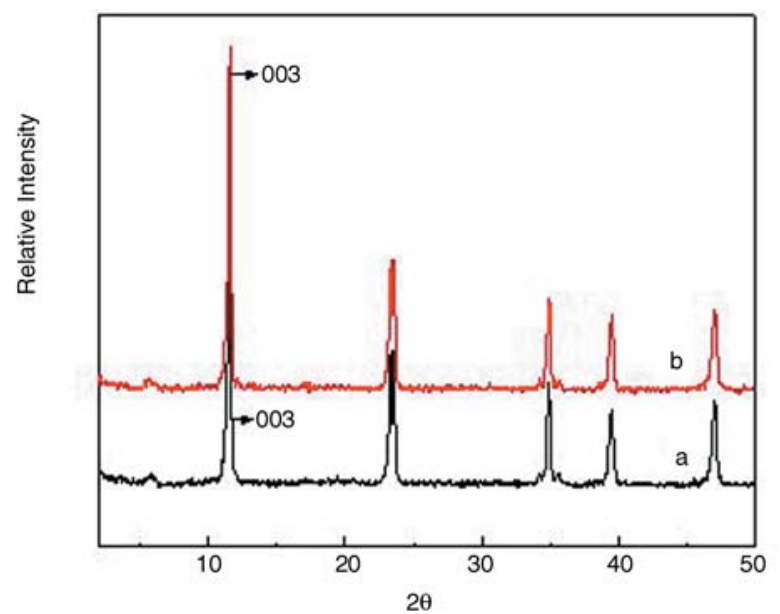

Figure 1. WAXRD patterns for $\mathrm{a}-\mathrm{Mg}$-Al hydrotalcite; $\mathrm{b}$ - organo-hydrotalcite

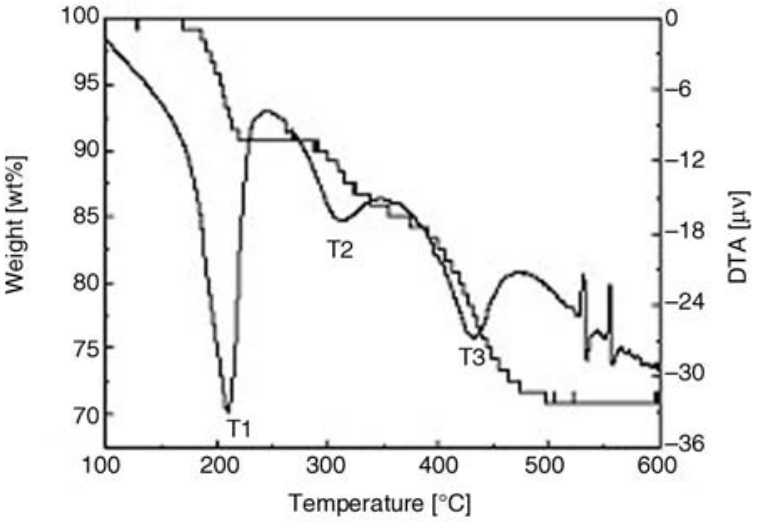

Figure 2. TGA analysis of $\mathrm{Mg}-\mathrm{Al}$ hydrotalcite

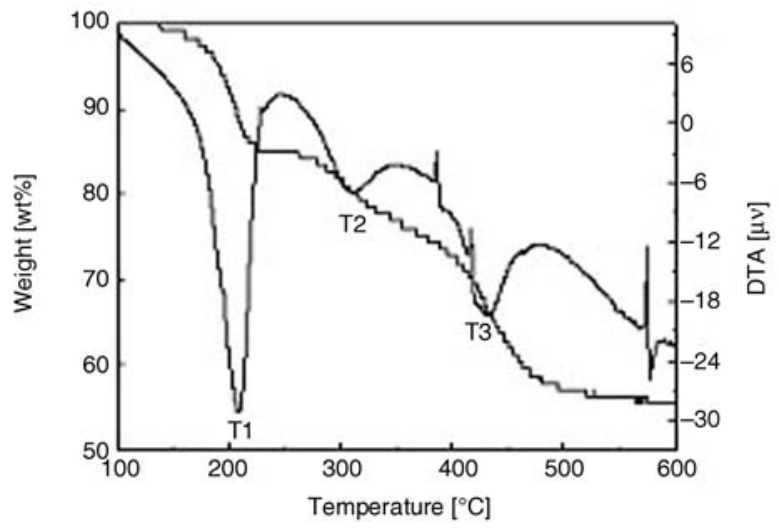

Figure 3. TGA analysis of organo-hydrotalcite

Table 2. Data of TGA analysis

\begin{tabular}{|l|l|l|l|}
\hline \multicolumn{1}{|c|}{ Sample } & $\mathbf{T}_{\mathbf{1}}\left[{ }^{\circ} \mathbf{C}\right] \sim \mathbf{w t} \mathbf{\%}$ & $\mathbf{T}_{\mathbf{2}}\left[{ }^{\circ} \mathbf{C}\right] \sim \mathbf{w t} \mathbf{\%}$ & $\mathbf{T}_{\mathbf{3}}\left[{ }^{\circ} \mathbf{C}\right] \sim \mathbf{w t} \%$ \\
\hline hydrotalcite & $209.9 \sim 90.8$ & $313.7 \sim 85$ & $433.5 \sim 70.8$ \\
\hline organo-hydrotalcite & $208.5 \sim 85.1$ & $310.9 \sim 76.0$ & $431.5 \sim 55.4$ \\
\hline
\end{tabular}

between hydrotalcite layers is important for the polymerization of $\varepsilon$-caprolactam and chain structure of copolymer. TGA analysis was used to determine the quantity of alanine between hydrotalcite layers. TGA curves of $\mathrm{Mg}$-Al hydrotalcite and organo-hydrotalcite were shown in Figure 2 and Figure 3 respectively. Both $\mathrm{Mg}-\mathrm{Al}$ hydrotalcite and organo-hydrotalcite have three weight-loss regions. The detailed data are listed in Table 2. After thermal decomposition the weight of Mg-Al hydrotalcite and organo-hydrotalcite residuals are $70.8 \mathrm{wt} \%$ and $55.4 \mathrm{wt} \%$ respectively. Because of the presence of water, decomposition products of analine ions and carbonic ions between layers of hydrotalcite released on heating, the content of intercalated alanine was calculated according to the formula

$\frac{\left.\mathrm{M}_{\mathrm{w}} \text { (alanine anion }\right)}{\mathrm{M}_{\mathrm{w}}(\text { alanine anion })-\mathrm{M}_{\mathrm{w}}(\text { carbonic anion })} \cdot(\mathrm{Rh}-\mathrm{Ro})=$ $48.4 \%)$ 
Rh: residual weight [\%] of hydrotalcite after thermal decomposition;

Ro: residual weight [\%] of organo-hydrotalcite after thermal decomposition.

Through simple mathematical computation, molar content of alanine in each gram of organo-hydrotalcite can be calculated as $5.44 \mathrm{mmol} / \mathrm{g}$.

To validate the result of TGA methods, absorbance analysis was used to determine the content of intercalated alanine. The result of absorbance analysis was $42 \%$ and similar to that of TGA methods. This approved that TGA method was a simple and effective method determining the content of intercalated alanine.

There exist two structures for layered minerals/ polymer nanocomposites: intercalated and exfoliated. WAXRD was used to explore the dispersion state of hydrotalcite in the products. The WAXRD patterns was shown in Figure 4. The results showed that the typical peak (003) $2 \theta$ of hydrotalcite shift

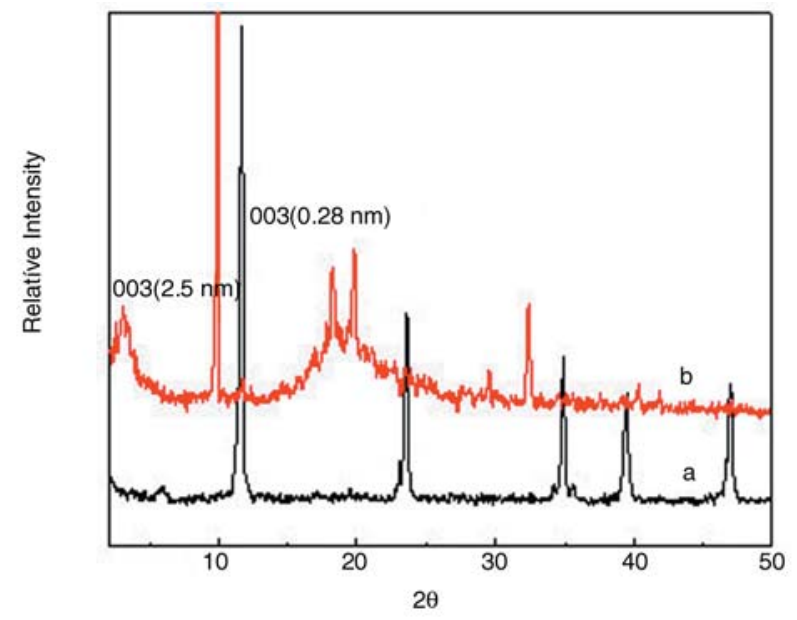

Figure 4. WAXRD patterns of the products containing $10 \%$ organo-hydrotalcite

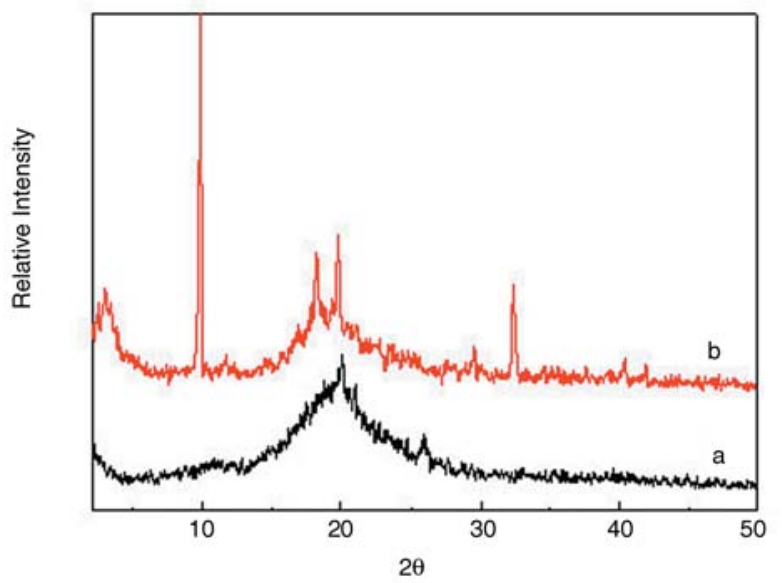

Figure 5. WAXRD patterns for a - LMW-PA6; b LMW-PA6 containing 10\% organo-hydrotalcite from $11.6^{\circ}$ to small angle $2.96^{\circ}$ after in situ polymerization. If the thickness of the brucite-like layer is assumed to be $0.48 \mathrm{~nm}$, the interlayer distance calculated according to Bragg formula changes from 0.28 to $2.5 \mathrm{~nm}$. This showed that alanine intercalated in hydrotalcite has initiated $\varepsilon$-caprolactam to polymerize and produced polymer chains enlarge the distance between layers. So the products belong to intercalated nanocomposites.

\subsection{Effect of hydrotalcite on the crystalloid of low-molecular-weight PA6}

PA6 generally has two crystalloids including $\alpha$ and $\gamma$ and usually exists in the $\alpha$ crystal form. Does hydrotalcite affect the crystal type of LMW-PA6? WAXRD patterns of LMW-PA6 and LMWPA6/hydrotalcite intercalated nanocomposites were compared (Figure 5.).

The result showed that LMW-PA6 prepared has two typical diffraction peaks of $\alpha$ crystalloid while LMW-PA6/hydrotalcite intercalated nanocomposites has a very obvious diffraction peak of the ? crystalloid $\left(2 \theta=19.7^{\circ}\right)$. We thought that limited space between layers of hydrotalcite hindered crystallization of LMW-PA6.

\subsection{Effect of hydrotalcite on the molecular weight of LMW-PA6}

Molecular weight and its distribution are important factors on property and processing of polymer. Hydrotalcite may affect molecular weight and its distribution of the products. GPC curves and the number average molecular weight $(\mathrm{Mn})$ of the products are shown in Figure 6. and Figure 7. respectively. Molecular weight distribution of the in situ polymerization products in the presence of organo-hydrotalcite has double peaks while that in the absence of organo-hydrotalcite has only one peak. At the same time, Mn of the products of in situ polymerization in the presence of organohydrotalcite is higher than that in the absence of organo-hydrotalcite. When organo-hydrotalcite is present, $\varepsilon$-caprolactam can polymerize by itself or may diffuse into interlayer gallery of hydrotalcite and polymerize there. Due to difference of end-cappings oleic acid reaction rate with $-\mathrm{NH}_{2}$ at the end of polymer chains, there existed two molecularweight polymers. Furthermore, the amount of organo-hydrotalcite didn't influence molecular 


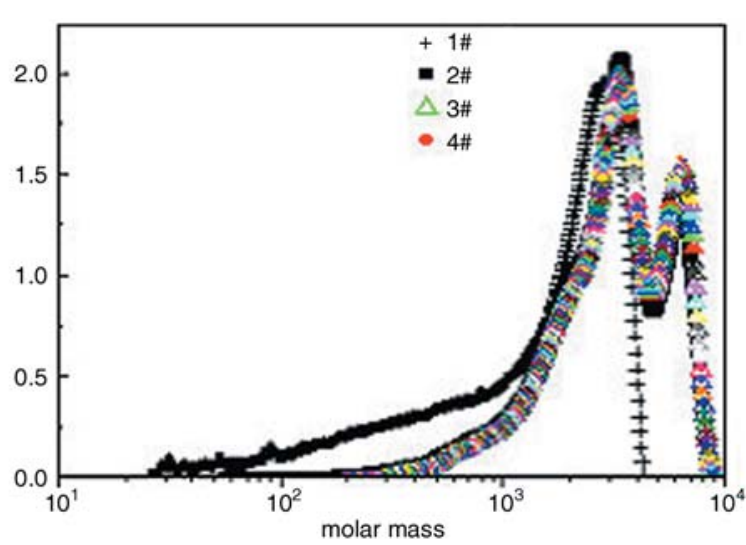

Figure 6. GPC curves of the products $1 \#$ - hydrotalcite content $0 \%$; 2\# - organo-hydrotalcite content $5 \%$; $3 \#$ - organo-hydrotalcite content $10 \%$; $4 \#$-organo-hydrotalcite content $10 \%$ without additional alanine

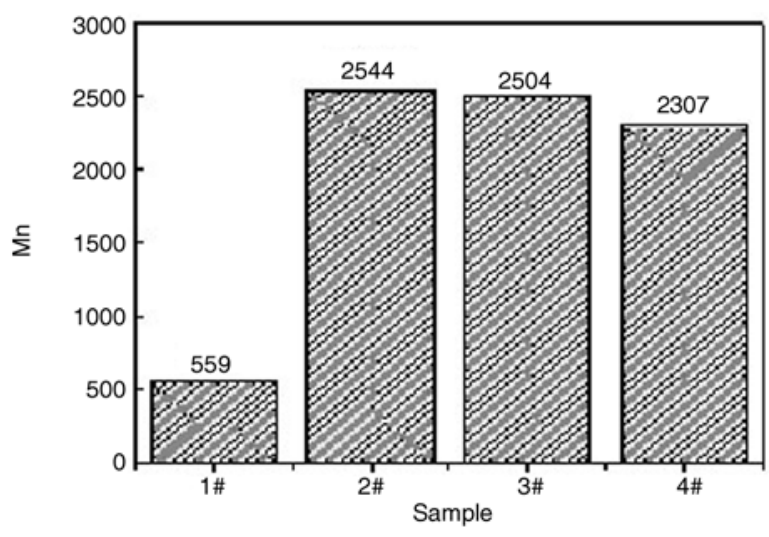

Figure 7. Number average molecular weight $(\mathrm{Mn})$ of the products $1 \#$ - hydrotalcite content $0 \%$; 2\# - organo-hydrotalcite content $5 \%$; $3 \#$ - organo-hydrotalcite content $10 \%$; 4 \# - organo-hydrotalcite content $10 \%$ without additional alanine

weight of the products. If additional alanine was not introduced, Mn of the products decreased slightly. As we know, the ratio between amount of $-\mathrm{NH}_{2}$ in monomer $\varepsilon$-caprolactam and alanine and amount of $-\mathrm{COOH}$ in end-cappings oleic acid affected molecular weight of the polymers. This was because the ratio between monomer and endcappings changes from 2.14 to 1.92 .

\section{Conclusions}

LMW-PA6/hydrotalcite intercalated nanocomposites were prepared via in situ polymerization in the presence of organo-hydrotalcite with alanine as an initiator at $150^{\circ} \mathrm{C}$. Though intercalated alanine doesn't change the interlayer distance of hydrotalcite, alanine in the interlayer gallery of hydrotalcite can initiate $\varepsilon$-caprolactam to polymerize and therefore LMW-PA6/hydrotalcite intercalated nanocomposites were prepared. There exsist $\gamma$ crystalloids of LMW-PA6 in LMW-PA6/hydrotalcite intercalated nanocomposites. The molecular weight distribution of LMW-PA6 in the intercalated nanocomposites has two peaks and added amounts of organo-hydrotalcite hardly influence molecular weight of LMWPA6. Without additional alanine $\varepsilon$-caprolactam can polymerize in the present of hydrotalcite and $\mathrm{Mn}$ of the products decreases slightly.

\section{References}

[1] Wu T-M., Liao C-S.: Polymorphism in nylon6/clay nanocomposites. Macromolecular Chemistry and Physics, 201, 2820-2825 (2000).

[2] Ranade A., D' Souza N. A., Gnade B., Dharia A.: Nylon-6 and montmorillonite-layered nanocomposites. Journal of Plastic Film and Sheeting, 19, 271-285 (2003).

[3] Rusu G., Rusu E.: Nylon6/SiO 2 nanocomposites synthesized by in situ anionic polymerization. High Performance Polymers, 18, 355-375 (2006).

[4] Chavarria F., Paul D. R.: Comparison of nanocomposites based on nylon 6 and nylon 66. Polymer, 45, 8501-8515 (2004).

[5] Rhutesh K., Shah P. K., Paul D. R.: Nylon 6 nanocomposites prepared by a melt mixing masterbatch. Polymer, 45, 2991-3000 (2004).

[6] Hasegawa N., Okamoto H., Kato M., Usuki A., Sato N.: Nylon 6/Na-montmorilllonite nanocomposites prepared by compounding nylon 6 with Na-montmorillonite slurry. Polymer, 44, 2933-2937 (2003).

[7] Miyata S.: Synthesis of hydrotalcite-like compounds and their structures and physico-chemical properties the systems $\mathrm{MgAlNO}_{3}, \mathrm{MgAlCl}, \mathrm{MgAlClO}_{4}, \mathrm{NiAlCl}$, ZnAlCl. Clays and Clay Minerals, 23, 369-372 (1975).

[8] Ulibarri M. A., Pavlovic I., Barriga C., Hermosín M. C., Cornejo J.: Adsorption of anion species on hydrotalcite-like compounds: effect of interlayer anion and crystallinity. Applied Clay Science, 18, 17-27 (2001).

[9] Li F., Duan X.: Applications of Layered Double Hydroxides. Springer, Berlin (2006).

[10] Vaccari A. Yamaoka T.: Preparation and catalytic properties of cationic and anionic clays. Catalysis Today, 41, 53-71 (1998).

[11] Coudray B. M., Lakshmi K. M., Kavita B., Venkat R. C., Koteswara R. K., Figueras F.: Aldol condensations catalysed by novel $\mathrm{Mg}$-Al-O-t-Bu hydrotalcite. Tetrahedron Letters, 39, 3555-3558 (1998).

[12] Sorrentino A., Gorrasi G., Tortora M., Vittoria V., Constantino U., Marmottini F., Padella F.: Incorporation of $\mathrm{Mg}$ - $\mathrm{Al}$ hydrotalcite into a biodegrad- 
able Poly( $\varepsilon$-caprolactone) by high energy ball milling. Polymer, 46, 1601-1608 (2005).

[13] Lee W. F., Chen Y. C.: Superabsorbent Polymeric Materials. XIV. Preparation and water absorbency of nanocomposite superabsorbents containing intercalated hydrotalcite. Journal of Applied Polymer Science, 94, 2417-2424 (2004).

[14] Vieille L., Moujahid E., Taviot-Gueho G., Cellier J., Besse J. P., Leroux F.: In situ polymerization of interleaved monomers: a comparative study between hydrotalcite and hydrocalumite host structures. Journal of Physics and Chemistry of Solids, 65, 385-393 (2004).

[15] Okamura A., Hirai T., Tanihara M.: Synthesis and properties of novel biodegradable polyamides containing $\alpha$-amino acids. Polymer, 43, 3549-3554 (2002).
[16] Marek M. J., Stehlícek J., Doskocilová D.: Synthesis and properties of copolymers consisting of aramide and poly(6-hexanelactam) blocks. European Polymer Journal, 31, 363-368 (1995).

[17] Franco L., Navarro E., Subirana J. A., Puiggali J.: Incorporation of glycine residues in even-even nylons disrupts their characteristic all-trans conformation. Polymer, 39, 5553-5560 (1998).

[18] Yang P. P., Su M. P., Yang X. W., Liu G. Z., Yu J. F., Wu T. H., Cho D. H., Chang T. S., Lee D. K.: Synthesis of high crystallinity hydrotalcite-like compounds with urea method. Chinese Journal of Inorganic Chemistry, 19, 485-490 (2003). 